\title{
Toward a standardised thermal-optical protocol for measuring atmospheric organic and elemental carbon: the EUSAAR protocol
}

\author{
F. Cavalli ${ }^{1}$, M. Viana ${ }^{2}$, K. E. Yttri ${ }^{3}$, J. Genberg ${ }^{4}$, and J.-P. Putaud ${ }^{1}$ \\ ${ }^{1}$ European Commission, Joint Research Centre, Institute for Environment and Sustainability, Climate Change Unit, via Enrico \\ Fermi 1, 21020 Ispra, Italy \\ ${ }^{2}$ Institute for Environmental Assessment and Water Research (IDAEA-CSIC), C/Lluís Solé i Sabarís s/n, 08028 Barcelona, \\ Spain \\ ${ }^{3}$ Department of Atmospheric and Climate Research Norwegian Institute for Air Research (NILU), P.O. Box 100, \\ 2027 Kjeller, Norway \\ ${ }^{4}$ Nuclear Physics, Department of Physics, Lund University, P.O. Box 118, 22100, Lund, Sweden
}

Received: 3 June 2009 - Published in Atmos. Meas. Tech. Discuss.: 1 October 2009

Revised: 8 January 2010 - Accepted: 11 January 2010 - Published: 26 January 2010

\begin{abstract}
Thermal-optical analysis is a conventional method for determining the carbonaceous aerosol fraction and for classifying it into organic carbon, OC, and elemental carbon, EC. Unfortunately, the different thermal evolution protocols in use can result in a wide elemental carbon-to-total carbon variation by up to a factor of five. In Europe, there is currently no standard procedure for determining the carbonaceous aerosol fraction which implies that data from different laboratories at various sites are of unknown accuracy and cannot be considered comparable. In the framework of the EU-project EUSAAR (European Supersites for Atmospheric Aerosol Research), a comprehensive study has been carried out to identify the causes of differences in the EC measured using different thermal evolution protocols; thereby the major positive and negative biases affecting thermal-optical analysis have been isolated and minimised to define an optimised protocol suitable for European aerosols. Our approach to improve the accuracy of the discrimination between OC and EC was essentially based on four goals. Firstly, charring corrections rely on faulty assumptions - e.g. pyrolytic carbon is considered to evolve completely before native EC throughout the analysis -, thus we have reduced pyrolysis to a minimum by favoring volatilisation of OC. Secondly, we have minimised the potential negative bias in EC determination due to early evolution of light absorbing carbon species at higher temperatures in the He-mode, including both native EC and combinations of native EC and pyrolytic carbon
\end{abstract}

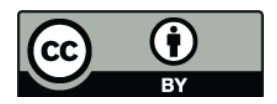

Correspondence to: F. Cavalli (fabrizia.cavalli@jrc.ec.europa.eu) potentially with different specific attenuation cross section values. Thirdly, we have minimised the potential positive bias in EC determination resulting from the incomplete evolution of $\mathrm{OC}$ during the He-mode which then evolves during the $\mathrm{He} / \mathrm{O}_{2}$-mode, potentially after the split point. Finally, we have minimised the uncertainty due to the position of the OC/EC split point on the FID response profile by introducing multiple desorption steps in the $\mathrm{He} / \mathrm{O}_{2}$-mode. Based on different types of carbonaceous PM encountered across Europe, we have defined an optimised thermal evolution protocol, the EUSAAR_2 protocol, as follows: step 1 in $\mathrm{He}, 200^{\circ} \mathrm{C}$ for 120 s; step 2 in $\mathrm{He} 300^{\circ} \mathrm{C}$ for $150 \mathrm{~s}$; step 3 in $\mathrm{He} 450^{\circ} \mathrm{C}$ for $180 \mathrm{~s}$; step 4 in $\mathrm{He} 650^{\circ} \mathrm{C}$ for $180 \mathrm{~s}$. For steps $1-4$ in $\mathrm{He} / \mathrm{O}_{2}$, the conditions are $500^{\circ} \mathrm{C}$ for $120 \mathrm{~s}, 550^{\circ} \mathrm{C}$ for $120 \mathrm{~s}, 700^{\circ} \mathrm{C}$ for $70 \mathrm{~s}$, and $850^{\circ} \mathrm{C}$ for $80 \mathrm{~s}$, respectively.

\section{Introduction}

Atmospheric elemental carbon, EC, is a product of incomplete combustion of fossil fuels in transportation, heating, and power generation, and of wood and biomass in residential heating, and agriculture activities. It is ubiquitous in the fine aerosol particles and appears at measurable levels even in the most remote locations (e.g. Putaud et al., 2004). EC has been observed to comprise from $8 \%$ to $17 \%$ of the atmospheric fine aerosol at European rural and urban background sites and kerbside sites, respectively (Putaud et al., 2004). The prevalence of aerosol EC has been a concern because of its role in adverse effects on human health (Highwood et al., 2006; Adar and Kaufman, 2007; Bérubé et al., 2007).

Published by Copernicus Publications on behalf of the European Geosciences Union. 
In recent years, scientific attention has also been given to its role as a driver of global warming (e.g. Jacobson, 2001; Ramanathan and Carmichael, 2008). Measurement of atmospheric EC has long been problematic, due to the fact that its physical and morphological properties are complex and variable. A variety of thermal and thermal-optical measurement techniques have been developed to measure organic carbon (OC) and EC. While these methods generally measure the same amount of total carbon (TC), the discrimination of TC into $\mathrm{OC}$ and $\mathrm{EC}$ is operationally defined with large differences in the amount of OC and EC measured by different methods (e.g. Schmid et al., 2001; Park et al., 2002; ten Brink et al., 2004; Park et al., 2005). In thermal-optical analyses, the carbonaceous material in aerosol particles deposited on a quartz-fibre filter is thermally desorbed according to a prescribed temperature protocol, first in an inert atmosphere $(\mathrm{He})$ and then in an oxidizing atmosphere $\left(\mathrm{He} / \mathrm{O}_{2}\right)$. Ideally, all OC would desorb in the inert gas stream while EC would combust in the oxidizing atmosphere at high temperature. In reality however, thermally unstable organic compounds pyrolyse in the He-mode to form pyrolytic carbon (PC) which then usually desorbs off the filter in the oxidizing atmosphere, like native EC. Incorrectly accounting for $\mathrm{PC}$ formation can very significantly bias the discrimination between OC and EC (e.g. Schmid et al., 2001; Schauer et al., 2003). To correct for pyrolysis, the optical properties of the sample are monitored before and during the analysis with a laser beam. As PC absorbs the laser light, light transmission and reflectance decrease while OC chars in the He-mode. When PC and EC are released from the filter in the $\mathrm{He} / \mathrm{O}_{2}$-mode, transmission and reflectance increase again and the point at which the transmission and reflectance reach the pre-pyrolysis value is used to discriminate OC and EC (split point).

IMPROVE and NIOSH have been the most widely thermal-optical protocols used in the atmospheric science community. Traditionally, the IMPROVE protocol (Chow et al., 1993) has been applied to samples from non-urban background sites in the US IMPROVE network; in 2005, the IMPROVE network started to apply the IMPROVE_A protocol, an only slightly modified version of IMPROVE thanks to refined measures of the sample temperature (Chow et al., 2007). The EPA/NIOSH (or STN) protocol (Peterson and Richards, 2002) has been applied to samples from urban sites in USA-EPA's Speciation Trends Network. These protocols differ in temperature set points - higher for EPA/NIOSH (e.g. the highest temperature in $\mathrm{He}$ is $900^{\circ} \mathrm{C}$ ) than for IMPROVE (e.g. the highest temperature in $\mathrm{He}$ is $550 / 580^{\circ} \mathrm{C}$ ) and in the residence times at each temperature step - typically longer for IMPROVE than for EPA/NIOSH. Moreover, the IMPROVE protocol uses the reflectance method to correct for charring, while the EPA/NIOSH protocol has adopted the transmittance method. Previous studies have demonstrated that such differences might significantly alter the measured amounts of OC and EC (e.g. Chow et al., 1993;
Conny et al., 2003; Chow et al., 2004). As of October 2009, the US urban network will also use the IMPROVE_A protocol (US EPA, 2006), and consistent OC and EC measurements will be obtained throughout the US urban and nonurban networks.

In Europe, there is currently no standard procedure for analysing the carbonaceous aerosol fraction, thus data from different laboratories at various sites are of unknown accuracy and cannot be compared. Addressing this issue is becoming more and more important as the EU Directive 2008/50/EC states that "measurements shall be made, at rural background locations [...] for the purposes of providing, as a minimum, information on the total mass concentration and the chemical speciation concentrations of fine particulate matter $\left(P M_{2.5}\right)$ ".

The EU-project EUSAAR (European Supersites for Atmospheric Aerosol Research, www.eusaar.net) integrates 20 high quality European regional background stations with the objective of harmonizing aerosol measurements of interest to air quality and global climate through coordinated protocols. Within this framework, efforts have been devoted to address major recommendations by Watson et al. (2005) for evaluating OC and EC measurement methods. We have identified the causes of differences in the EC measured using different thermal evolution protocols and thereby isolated and minimised the major positive and negative biases affecting thermal-optical analysis. As a result of this work, we defined a new protocol, EUSAAR_2 (Table 1), optimised for analysing carbonaceous aerosols at European regional background sites.

\section{Methods}

\subsection{Samples and analysis}

Five different types of samples were investigated in this study: i) ambient aerosol samples collected on quartz-fibre filters at four different background sites of the EUSAAR network, representing regionally distinct particulate matter: Birkenes (Norway), K-Puszta (Hungary), Ispra (Italy), and Montseny (Spain); ii) filters spiked with fulvic acid from the Suwannee River, which can mimic humic-like-substances, abundant in the fine atmospheric aerosol (Hoffer et al., 2006); iii) filters spiked with levoglucosan, a major component of wood smoke aerosol; iv) samples of both biogenic and anthropogenic secondary organic aerosol (SOA) generated in smog chamber photo-oxidations of $\alpha$-pinene and toluene, respectively; v) light-absorbing-carbon-only (LAC-only) samples generated by thermal treatment of ambient aerosol samples (Yu and Li, 2003), which contain a mixture of pyrolysed organic carbon, $\mathrm{PC}$, and native EC; and vi) filter spiked with mixtures of water-soluble inorganic ions and water-soluble organic carbon (WSOC), which have been shown mainly responsible for charring (Andreae and Gelencser, 2006) . 
Table 1. Temperature protocols used to analyse samples in the present work: temperature set point and residence time are reported. EUSAAR_2 protocol temperature set points and residence times are also reported.

\begin{tabular}{|c|c|c|c|c|c|c|c|c|c|}
\hline & EPA/NIOSH ${ }^{b}$ & NIOSH 5040 & IMPROVE $^{c}$ & $\begin{array}{c}\text { EUSAAR_1 } \\
\text { short }\end{array}$ & $\begin{array}{c}\text { EUSAAR_1 } \\
\text { Long }\end{array}$ & $\mathrm{He} 4-550$ & $\mathrm{He} 4-750$ & $\mathrm{He} 4-850$ & EUSAAR_2 \\
\hline STEP & $\begin{array}{l}T \text {, duration } \\
{ }^{\circ} \mathrm{C}, \mathrm{s}\end{array}$ & $\begin{array}{l}T \text {, duration } \\
{ }^{\circ} \mathrm{C}, \mathrm{s}\end{array}$ & $\begin{array}{l}T \text {, duration } \\
{ }^{\circ} \mathrm{C}, \mathrm{s}\end{array}$ & $\begin{array}{c}T \text {, duration } \\
{ }^{\circ} \mathrm{C}, \mathrm{s}\end{array}$ & $\begin{array}{c}T \text {, duration } \\
{ }^{\circ} \mathrm{C}, \mathrm{s}\end{array}$ & $\begin{array}{l}T \text {, duration } \\
{ }^{\circ} \mathrm{C}, \mathrm{s}\end{array}$ & $\begin{array}{l}T \text {, duration } \\
{ }^{\circ} \mathrm{C}, \mathrm{s}\end{array}$ & $\begin{array}{l}T \text {, duration } \\
{ }^{\circ} \mathrm{C}, \mathrm{s}\end{array}$ & $\begin{array}{c}T \text {, duration } \\
{ }^{\circ} \mathrm{C}, \mathrm{s}\end{array}$ \\
\hline $\mathrm{He} 1$ & 310,60 & 250,60 & $120,150-580$ & 200,120 & 200,180 & 200,180 & 200,180 & 200,180 & 200,120 \\
\hline $\mathrm{He} 2$ & 475,60 & 500,60 & $250,150-580$ & 300,150 & 300,240 & 300,240 & 300,240 & 300,240 & 300,150 \\
\hline $\mathrm{He} 3$ & 615,60 & 650,60 & $450,150-580$ & 450,180 & 450,240 & 450,240 & 450,240 & 450,240 & 450,180 \\
\hline $\mathrm{He} 4$ & 900,90 & 850,90 & $550,150-580$ & 650,180 & 650,240 & 550,240 & 750,240 & 850,240 & 650,180 \\
\hline $\mathrm{He} / \mathrm{O}_{2} 1^{\mathrm{a}}$ & 600,45 & 650,30 & $550,150-580$ & 550,240 & 550,300 & 550,300 & 550,300 & 550,300 & 500,120 \\
\hline $\mathrm{He} / \mathrm{O}_{2} 2$ & 675,45 & 750,30 & $700,150-580$ & 850,150 & 850,180 & 850,180 & 850,180 & 850,180 & 550,120 \\
\hline $\mathrm{He} / \mathrm{O}_{2} 3$ & 750,45 & 850,30 & $800,150-580$ & & & & & & 700,70 \\
\hline $\mathrm{He} / \mathrm{O}_{2} 4$ & 825,45 & 940,120 & & & & & & & 850,80 \\
\hline $\mathrm{He} / \mathrm{O}_{2} 5$ & 920,120 & & & & & & & & \\
\hline
\end{tabular}

a A mix of $2 \%$ oxygen in UHP helium.

$\mathrm{b}$ The temperature program for the EPA/NIOSH method is reported in Peterson and Richards (2002).

c The residence time at each temperature in the IMPROVE protocol depends on when the flame ionization detector (FID) signal returns to the baseline to achieve well-defined carbon fractions.

The samples were analysed using a Sunset Laboratory Dual-Optical Carbonaceous Analyser. Table 1 lists the NIOSH, the IMPROVE, the EUSAAR_1 long and short and the EUSAAR_2 protocols tested in the experiments; in addition, variants of the EUSAAR_1 long protocol were tested, in which the temperature of the last step in the He-mode was modified to $550^{\circ} \mathrm{C}, 750^{\circ} \mathrm{C}$ and $850^{\circ} \mathrm{C}$. We refer to these protocols as He4-550, He4-750 and He4-850, respectively. In total, 450 samples were analysed with the various protocols for a total run number of 600 .

In the EUSAAR_2 protocol, optical correction of charring was performed by transmittance (laser wavelength $678 \mathrm{~nm}$ ). Visual investigations of samples at different temperature stages of analysis indicate that formation of pyrolytic carbon occurs throughout the filter section (Chow et al., 2004). Analyses of undenuded and denuded aerosol samples - using a carbon honeycomb denuder with a proven efficiency $>80 \%$ in removing volatile organic compounds - were performed applying the EUSAAR_2 protocol and both reflectance and transmittance optical corrections for charring. The ratios between reflectance- and transmittance-corrected EC concentrations obtained from the two different sampling conditions were similar, $1.70 \pm 0.01$, on average; therefore, in contrast to the hypothesis of Chow et al. (2004), charring of volatile organics absorbed in the filter (as a result of positive sampling artifacts) plays a negligible role on the difference between EC_TOR and EC_TOT when the analytical protocol EUSAAR 2 is used. On the contrary, the formation of pyrolytic carbon throughout the filter section must arise from the charring of particulate $\mathrm{OC}$ which diffuses in the filter during the sampling (Petzold and Schönlinner, 2004) or analysis phase (Chow et al., 2004). Several studies have demonstrated that the removal of particulate WSOC and/or brown carbon by extraction with water or organic solvents prior to thermochemical analysis considerably reduces charring (Andreae and Gelencsèr, 2006) which also shows that the formation of pyrolytic carbon arise from charring of particulate OC. As total carbon includes also the pyrolytic carbon formed in the inner part of the filter, a proper optical correction should account for the charring that occurs through the whole filter as transmittance does.

\section{Results and discussion}

In thermal-optical analyses, the accurate discrimination between OC and EC relies upon either one or the other of the following two assumptions being correct: 1) PC formed during the He-mode is assumed to have the same specific attenuation cross section $(\sigma)$ as the atmospheric native EC. If so, regardless of when PC and EC actually evolve from the filter during the analysis, the desorbed carbon beyond the split point is equivalent to the mass of native EC. 2) Alternatively, all $\mathrm{PC}$ formed during the He-mode is assumed to evolve from the filter before the native EC throughout the analysis. In this case despite possible differences in $\sigma$ of PC and EC, the post split point carbon mass represents the true native EC. Previous studies have however demonstrated that neither of these assumptions always holds. PC and EC have been found to co-evolve from the $\mathrm{He} / \mathrm{O}_{2}$-mode and, even prematurely, from the He-mode at high temperatures; moreover, they have been shown to have significantly different values of $\sigma$ (e.g. Chow et al. 2004; Yang and Yu, 2002; Yu et al., 2002; Subramanian et al., 2006; Han et al, 2007). There are, then, inherent potential biases in both directions in the determination of OC and EC. To determine best practice, a thermal-optical 
Table 2. TC OC and PC, in $\mu \mathrm{gC} \mathrm{cm}{ }^{-2}$ units, obtained from analysis of aerosol samples using both a EPA/NIOSH thermal protocol (Peterson and Richards, 2002) and a version modified by the addition of steps at low temperature. OC is reported as the organic carbon peaks, evolved in the He-mode prior to and after $300^{\circ} \mathrm{C}$; PC is estimated by the sample transmittance over the entire He-mode and assuming a specific attenuation cross section of $45 \mathrm{~m}^{2} / \mathrm{gC}$.

\begin{tabular}{|c|c|c|c|c|c|}
\hline \multirow[t]{2}{*}{ THERMAL } & \multirow[t]{2}{*}{ sample } & \multirow[t]{2}{*}{$\mathrm{TC} \mu \mathrm{g} \mathrm{cm}^{-2}$} & \multicolumn{2}{|c|}{$\mathrm{OC} \mu \mathrm{g} \mathrm{cm}^{-2}$} & \multirow[t]{2}{*}{$* \mathrm{PC} \mu \mathrm{g} \mathrm{cm}^{-2}$} \\
\hline & & & $\leq 300^{\circ} \mathrm{C}$ & $>300^{\circ} \mathrm{C}$ & \\
\hline NIOSH & 1 & 11.59 & 2.41 & 4.27 & 3.87 \\
\hline Modified NIOSH & 1 & 11.51 & 2.81 & 4.20 & 3.36 \\
\hline NIOSH & 2 & 12.79 & 2.82 & 4.54 & 1.99 \\
\hline Modified NIOSH & 2 & 12.79 & 3.29 & 4.60 & 1.67 \\
\hline NIOSH & 3 & 8.33 & 1.93 & 3.05 & 3.62 \\
\hline Modified NIOSH & 3 & 8.30 & 2.21 & 2.98 & 3.12 \\
\hline
\end{tabular}

*PC peak area estimated from the sample transmittance.

protocol was, therefore, developed to minimise the effects of those events during the analysis that cause these biases in the OC/EC split. We have attempted to satisfy the following optimisation criteria:

1. charring is reduced to a minimum, to minimise in turn the effect of any difference in $\sigma$ of PC and EC on the accuracy of the optical correction and, thus, of the discrimination between OC and EC.

2. evolution and/or pyrolysis of OC is completed by the end of the He-mode to avoid any residual unevolved and uncharred $\mathrm{OC}$ evolving in the $\mathrm{He} / \mathrm{O}_{2}$-mode. This, in turn, reduces the uncontrolled risk that a fraction of non-light-absorbing organic carbon evolves even after the OC/EC split and positively biases the measured EC.

3. premature evolution of LAC during the He-mode is minimised to prevent the early evolution of LAC species containing native EC. In such cases the resulting postsplit EC might be altered, because of possibly different $\sigma$ of EC and PC.

4. multiple desorption steps are designed for the $\mathrm{He} / \mathrm{O}_{2}$ mode to ensure that the OC/EC split point occurs where the FID response profile is low; minimising the uncertainty in the split point position will minimise uncertainty in the discrimination of $\mathrm{OC}$ and EC.

With this in mind, the following key parameters were investigated in designing the optimised EUSAAR_2 thermal protocol: 1) the steps at low temperature; 2) the He-mode maximum temperature; 3 ) the residence time of each temperature step; and 4) the temperature steps in the $\mathrm{He} / \mathrm{O}_{2}$-mode.

\subsection{Temperature set points}

\subsubsection{Low temperature steps in the He-mode}

A set of three samples collected in Ispra in the springsummer has been analysed using the EPA/NIOSH thermal protocol (Peterson and Richards, 2002) and a modified version of this protocol. The two protocols differ in the low temperature steps applied in the He-mode; the EPA/NIOSH protocol has a single step at $310^{\circ} \mathrm{C}$ of $60 \mathrm{~s}$ (Table 1) whereas the modified version of the EPA/NIOSH protocol uses two steps at $200{ }^{\circ} \mathrm{C}$ and $300^{\circ} \mathrm{C}$ with significantly longer residence time of $180 \mathrm{~s}$ and $240 \mathrm{~s}$, respectively.

Results show that the amount of OC evolving up to a temperature of about $300{ }^{\circ} \mathrm{C}$ is $15.7 \pm 1.3 \%$ higher in the modified-EPA/NIOSH than in the original EPA/NIOSH protocol (Table 2). The additional step at $200{ }^{\circ} \mathrm{C}$ and longer times favour the release of organic carbon prior to the more aggressive heating steps where pyrolysis occurs. The amount of OC available for evolution and/or pyrolysis at higher temperatures is thus reduced. Interestingly, the overall amount of PC formed as measured by the sample transmittance and assuming $\sigma=45 \mathrm{~m}^{2} / \mathrm{gC}$ (Subramanian et al., 2007 and Boparai et al., 2007), is on average $16.8 \pm 1.9 \%$ smaller compared to the EPA/NIOSH protocol. In other words, the OC that evolves at lower temperatures in the modified protocol would otherwise char at higher temperature steps in the EPA/NIOSH method. In agreement with Yu et al. (2002) and Chow et al. (2004), our results indicate that the extent of charring is strongly dependent on the temperature set-points, and secondly that prolonging residence times can favour a more complete carbon evolution, which, consequently, reduces charring formation. Because of unequal $\sigma$ for $\mathrm{PC}$ and $\mathrm{EC}$, the reduction in charring improves, in turn, the accuracy of the OC/EC split.

Additional ten samples collected in Ispra have also been analysed both in presence and absence of oxygen (He/Oxygen mixture 98:2) at the two steps at low temperature. Our results show negligible differences in the 

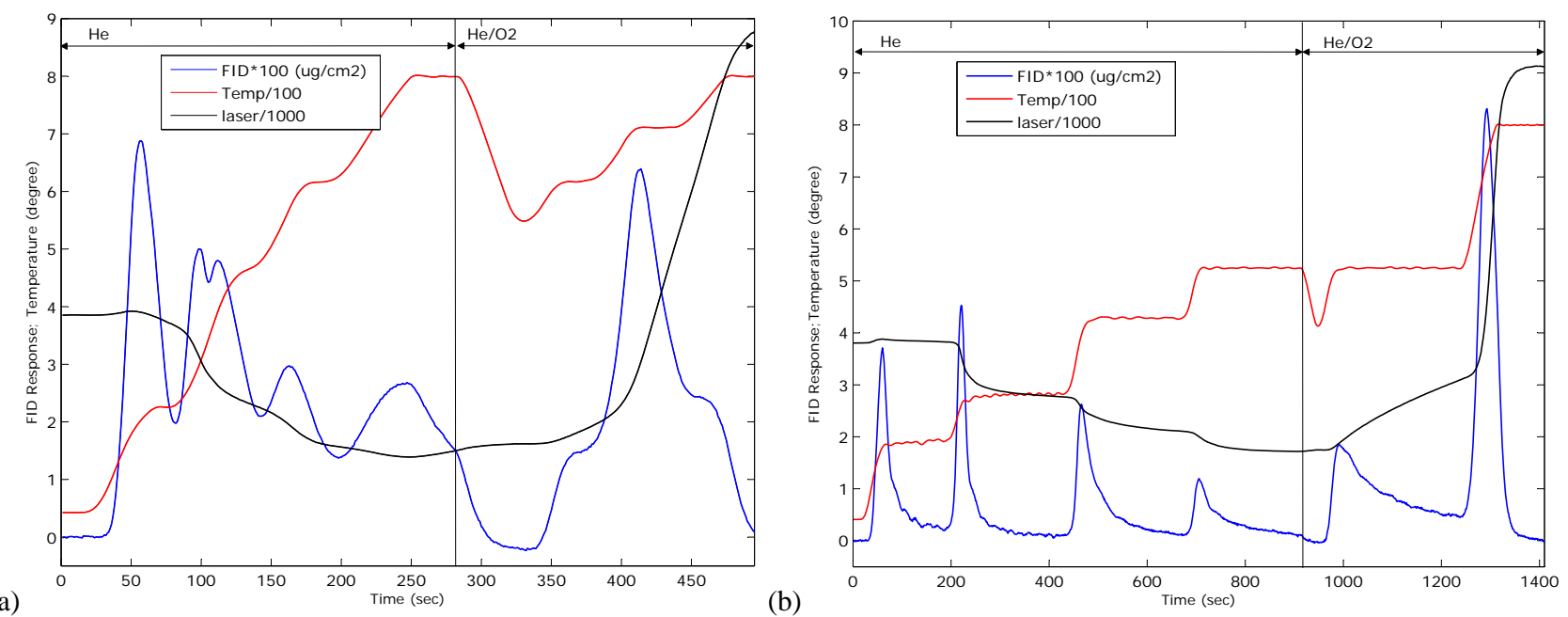

Fig. 1. Thermograms from the analysis of a typical ambient $\mathrm{PM}_{2.5}$ sample collected in Ispra, with (a) a NIOSH-type and (b) a He-550 protocol.

amounts of PC when oxygen-containing versus oxygen-free carrier gas is used for the lowest temperature steps. Therefore, taking into consideration the risk of EC combustion in an oxidizing atmosphere when temperature approaches $340^{\circ} \mathrm{C}$, and the potential temperature deviation from setpoints in the Sunset Lab. Instrument (Chow et al., 2005), an inert atmosphere was finally selected for the first two steps at low temperature, at $200{ }^{\circ} \mathrm{C}$ and $300{ }^{\circ} \mathrm{C}$, in the optimised protocol.

\subsubsection{Maximum He-mode temperature and premature LAC evolution}

Figure 1a shows a thermogram obtained from the analysis of an ambient $\mathrm{PM}_{2.5}$ aerosol sample collected in spring in Ispra (IT) using a NIOSH-type thermal protocol (NIOSH, 1999) with the maximum He-mode temperature of $850^{\circ} \mathrm{C}$. The transmission of laser light through the sample decreases through much of the He-mode due to PC formation; it reaches a minimum value partway through the $850^{\circ} \mathrm{C}$ step in $\mathrm{He}$ and then begins increasing, indicating the premature evolution of LAC. This phenomenon is not specific to Ispra samples: aerosol samples from Birkenes (NO), K-Puszta (HU), and Montseny (ES) also exhibited a rise in the laser transmission signal during the highest temperature step (See examples in Fig. S1 from the Supporting Information, http://www.atmos-meas-tech.net/3/79/ 2010/amt-3-79-2010-supplement.pdf), and many other examples are reported in the literature (e.g. Chow et al., 2001; Yu et al., 2002). At high temperatures, inorganic oxides, part of the filter deposit, can supply oxygen promoting combustion of LAC in an inert environment (Fung, 1990). In the event of the evolution of LAC in the He-mode of the analysis, the critical issue is to determine the type of LAC that evolves. Yu et al. (2002) suggest that it is PC. If the LAC evolving in the He-mode at high temperature is pure PC this does not produce any bias in OC and EC determination. However, Subramanian et al. (2006) demonstrated more recently that the LAC evolving in helium at high temperature can be either native EC or PC or a combination of them. And EC and PC cannot be accurately split using the laser signal since they were reported to have generally different $\sigma$ values (Chow et al., 2004 and Subramanian et al., 2006). Indeed, literature values of $\sigma$ for native EC deposited on quartz filters range from $8.1 \mathrm{~m}^{2} / \mathrm{gC}$ to $25.4 \mathrm{~m}^{2} / \mathrm{gC}$ for solvent-extracted ambient samples (Gundel et al., 1984; Liousse et al., 1993; Petzold et al., 1997; Subramanian et al., 2006), whereas the reported $\sigma$ for PC are almost always greater: in particular, $35 \mathrm{~m}^{2} / \mathrm{gC}$ is found for Pittsburgh samples (Subramanian et al., 2006), $52.8 \pm 10.6 \mathrm{~m}^{2} / \mathrm{gC}$ for Fresno samples and $48.5 \pm 3.9 \mathrm{~m}^{2} / \mathrm{gC}$ is reported for IMPROVE network samples (Chow et al., 2004). If $\sigma$ of PC is larger than $\sigma$ of EC, premature evolution in the He-mode of LAC containing EC will lead a He4-850 protocol like NIOSH-type (Fig. 1a) to underestimate the native EC amount. A solution is to lower the maximum temperature of the He-mode. Fig. 1b shows the thermogram from a He4-550 protocol (Table 1), such as IMPROVE, of the same sample as in Fig. 1a. The laser signal reaches its minimum value at $550^{\circ} \mathrm{C}$ and does not increase until the $\mathrm{He} / \mathrm{O}_{2}$-mode, indicating no loss of LAC in the He-mode. A series of thermal-optical analyses of twelve LAC-only samples were therefore performed to identify the temperature at which premature evolution of LAC starts and to assess the extent of this bias. LAC-only samples were generated by thermal treatment of ambient aerosol samples according to the method proposed by $\mathrm{Yu}$ and $\mathrm{Li}$ (2003), to form a mixture of PC and native EC. The LAC-only 
samples were analysed using a thermal protocol with varying maximum temperatures in the He-mode of $650^{\circ} \mathrm{C}, 750{ }^{\circ} \mathrm{C}$ and $850^{\circ} \mathrm{C}$. Increasing the maximum He-mode temperature caused an increase in the fraction of LAC evolving during that step. On average $2.5 \pm 2.4 \%, 16.2 \pm 5.9 \%$ and $21.2 \pm 4.4 \%$ of the total LAC was found to prematurely evolve in $\mathrm{He}$ at $650^{\circ} \mathrm{C}, 750^{\circ} \mathrm{C}$ and $850^{\circ} \mathrm{C}$, respectively (Fig. S2 from Supporting Information, http://www.atmos-meas-tech.net/3/ 79/2010/amt-3-79-2010-supplement.pdf). These observations suggest that the underestimation of the amount of EC measured in ambient $\mathrm{PM}_{2.5}$ aerosol samples using He4-650, He4-750 and He4-850 protocols could increase as the maximum He-mode temperature increases; and secondly that the potential biases produced by a protocol with the maximum temperature in the He-mode of $650^{\circ} \mathrm{C}$, as the EUSAAR protocol, are quite moderate, if not negligible.

\subsubsection{Maximum He-mode temperature and organic carbon}

Lowering the maximum temperature of the peak He-mode below $850^{\circ} \mathrm{C}$ certainly improves the accuracy of the OC/EC split by avoiding the premature evolution of LAC. The major concern becomes then the possibility that OC will not totally volatilize or completely pyrolyse during the He-mode of the analysis, and thus evolve into the $\mathrm{He} / \mathrm{O}_{2}$-mode instead. In these circumstances, there is an uncontrolled risk that a fraction of OC evolves even after the OC/EC split point and is erroneously measured as native EC. To minimise the potential of this positive bias for EC, we determined which temperature is necessary to produce total volatilization or pyrolysis of $\mathrm{OC}$ in the He-mode. We analysed quartz filters loaded with i) SOA, both anthropogenic and biogenic, ii) levoglucosan, and iii) fulvic acid. The selected species represent some of the major components of the OC aerosol fraction and the filters analysed did not contain EC. The protocol used for these tests has the following temperature steps in the He-mode: $550{ }^{\circ} \mathrm{C}, 650^{\circ} \mathrm{C}, 750^{\circ} \mathrm{C}$ and $850^{\circ} \mathrm{C}$, each of $240 \mathrm{~s}$; three replicates for each organic compound-spiked filters were obtained. Thermograms of these analyses are shown in Fig. 2. The time derivative of the laser transmission is used to measure the formation or release of light-absorbing carbon during the analysis and is expressed as negative carbon in the He-mode and positive carbon in the $\mathrm{He} / \mathrm{O}_{2}$-mode; dividing this by an appropriate $\sigma$ gives an estimate of the absorbing carbon formed or lost, which complements standard thermal-optical analysis output (Bond, personal communication, 2007). A detailed description of the calculation is given in Boparai et al. (2007). Thermograms 2a-2d clearly show that at maximum He-mode temperatures $\leq 550^{\circ} \mathrm{C}$, a significant fraction of organic carbon is neither evolved nor completely pyrolysed in the He-mode: organic carbon still evolves (FID signal) and chars (laser signal time derivative) at temperatures higher than $550^{\circ} \mathrm{C}$. Our findings imply that analysis of these samples using a He4-550 protocol results in a significant fraction of organic carbon evolving in the $\mathrm{He} / \mathrm{O}_{2}$-mode, potentially even after the OC/EC split point. Consequently, EC as defined by a He4-550 protocol such as IMPROVE, should be considered overestimates of the native EC. To prevent this potential overestimation of EC, it is advisable to increase the maximum He-mode temperature above $550^{\circ} \mathrm{C}$; however this temperature should be lower than $850^{\circ} \mathrm{C}$ to minimise the premature LAC evolution.

Figure 2a shows that a large fraction (91\%) of the anthropogenic SOA carbon evolves and/or pyrolyses by the end of the $650{ }^{\circ} \mathrm{C}$ step in the He-mode of the analyses. The results for biogenic SOA and levoglucosan (Fig. 2b and Fig. 2c) are quite similar: $98 \%$ of the carbon evolves and/or pyrolyses as the analysis completed the step at $650^{\circ} \mathrm{C}$. On the contrary, ca. $80 \%$ only of the carbon from fulvic acid evolves and/or pyrolyses by the end of the $650{ }^{\circ} \mathrm{C}$ step. Thus, in a protocol with a maximum temperature in the He-mode of $650^{\circ} \mathrm{C}$, a fraction of fulvic acid carries over into $\mathrm{He} / \mathrm{O}_{2}$-mode. Fulvic acid is a high molecular weight substance with a marked degree of aromaticity and, therefore, has a refractory character. But carrying out the analysis at temperatures higher than $650^{\circ} \mathrm{C}$ a large release of pyrolysed carbon is observed (Fig. 2d): the corresponding FID carbon peak thus consists of OC and evolved PC. In this circumstance, it is impossible to demonstrate that increasing the temperature above $650{ }^{\circ} \mathrm{C}$ would significantly improve the $\mathrm{OC}$ fraction evolved and/or pyrolysed in the He-mode. In addition, similar experiments were performed with thirty ambient atmospheric aerosol samples collected at the previously mentioned four EUSAAR sites. Results confirm that, for most samples, OC totally evolves or chars as the analyses completed the $650^{\circ} \mathrm{C}$ step. In a few cases, only a fraction of maximum $10 \%$ of OC evolves at higher temperatures. Again, at higher temperatures (from $750^{\circ} \mathrm{C}$, and even more at $850^{\circ} \mathrm{C}$ ), premature evolution of LAC occurs; the FID carbon peak is thus the sum of OC and prematurely evolved LAC and, in such case, it is impossible to conclude that increasing the temperature above $650{ }^{\circ} \mathrm{C}$ would significantly improve $\mathrm{OC}$ fraction evolved in the He-mode. $650{ }^{\circ} \mathrm{C}$, The highest temperature reached in the He-mode by the EUSAAR_2 protocol, appears as the best compromise between adequate evolution and/or pyrolysis of $\mathrm{OC}$ and a minimum LAC pre-combustion in the He-mode.

Finally, five samples collected in Ispra in different seasons were subjected to water extraction, filtration to remove EC residuals, and concentration of the extract to a suitable volume for filter spiking. The water extracts contain a mixture of water-soluble inorganic ions and WSOC which have been shown to be mainly responsible for charring. Punches spiked with the water extracts ( 1 to $7 \mu \mathrm{g} \mathrm{cm}^{-2}$ ) were then analysed using the EUSAAR_2 protocol. Results show that the EUSAAR_2 protocol detects as pure OC the carbon content of samples actually containing only a mixture of WSOC and inorganics, and that it can therefore properly correct for pyrolitic carbon formation. 
(a)

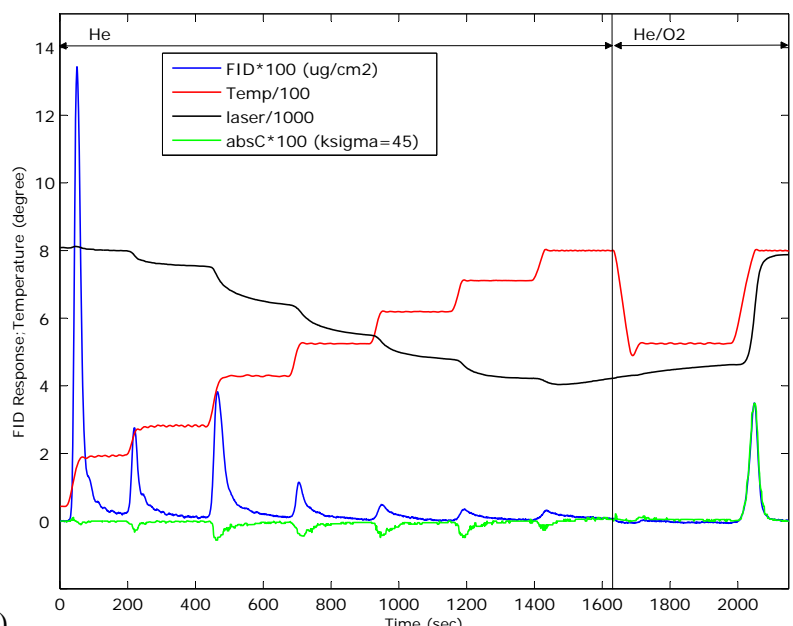

(c)

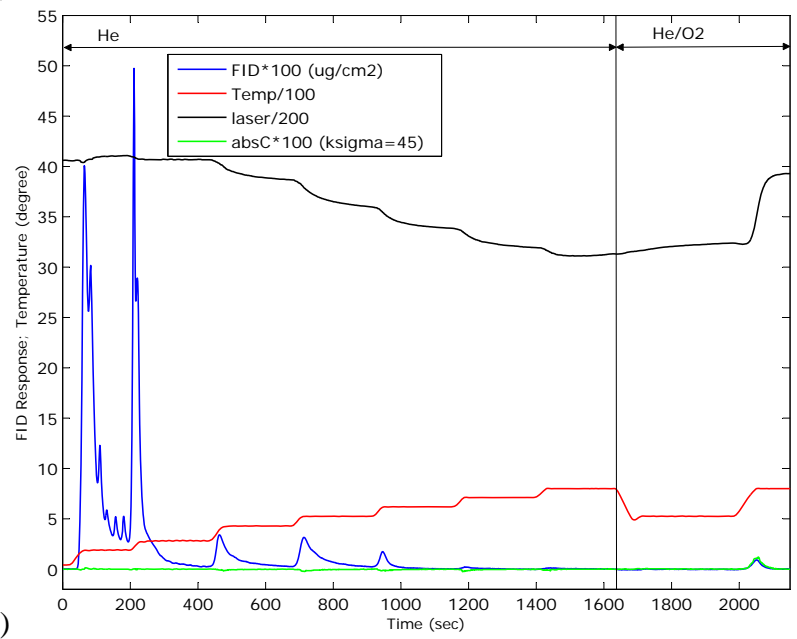

(b)
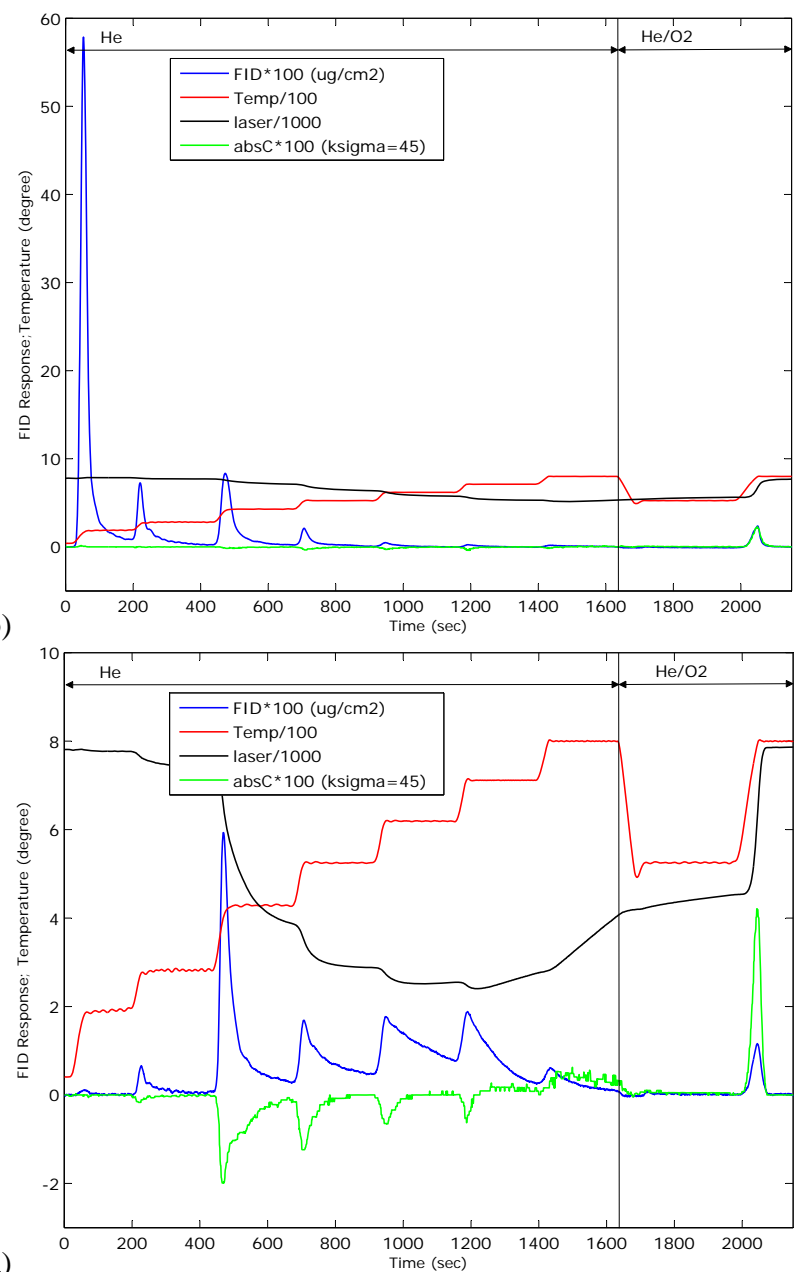

Fig. 2. Thermograms from the analysis of toluene photo-oxidation aerosol products (a), $\alpha$-pinene photo-oxidation aerosol products (b), levoglucosan (c), and fulvic acid (d). The protocol used for the analysis has the following steps in the He-mode: He- 4 at $550{ }^{\circ} \mathrm{C}$, He- 5 at $650^{\circ} \mathrm{C}$, He- 6 at $750^{\circ} \mathrm{C}$ and $\mathrm{He}-7$ at $850^{\circ} \mathrm{C}$, each of $240 \mathrm{~s}$. absC $\left.* 100 \mathrm{ksigma}=45\right)$ is the amount of PC formed/released, multiply by 100 , as calculated by the laser attenuation and $\sigma=45 \mathrm{~m}^{2} / \mathrm{gC}$ (Boparai et al., 2007).

\subsubsection{Maximum He-mode temperature and carbonatic carbon}

The contribution of carbonatic carbon (CC) to TC at regional background sites in Europe is generally $<5 \%$, but contributions $>30 \%$ can occur. Depending on the chemical nature of the carbonate species - e.g. $\mathrm{CaCO}_{3}, \mathrm{CaMg}\left(\mathrm{CO}_{3}\right)_{2}, \mathrm{Na}_{2} \mathrm{CO}_{3}$ etc. - and on the crystal structure - calcite, aragonite, etc. ,$- \mathrm{CC}$ evolves over a broad range of temperatures. Thermaloptical analyses of filters spiked with $\mathrm{Na}_{2} \mathrm{CO}_{3}$ solution and with $\mathrm{CaCO}_{3}$ suspension indicate that $\mathrm{CC}$ evolves mainly over a range of temperature between $450^{\circ} \mathrm{C}$ and $650{ }^{\circ} \mathrm{C}$. These results are supported by analyses of natural calcite from Spain (grain dimension $\leq 300 \mu \mathrm{m}$ ) (Fig. 3).

Natural calcite evolves in the He-mode with the EUSAAR_2 and the NIOSH protocol, and will be detected as $\mathrm{OC}$, whereas it evolves in the $\mathrm{He} / \mathrm{O}_{2}$-mode with the IMPROVE protocol and will possibly be detected as EC.
Neither the NIOSH protocol nor the IMPROVE protocol address definitely this issue of CC. The NIOSH method 5040 recommends fumigation of the aerosol samples with $\mathrm{HCl}$ prior to thermal-optical analysis to eliminate any contribution of CC to OC and/or EC signal. However, fumigation with $\mathrm{HCl}$ has been shown to cause artificial loss of volatile organic acids (Chow et al., 1993) and to induce intense charring phenomena in ambient aerosol samples (Jankowski et al., 2008). Moreover, the $\mathrm{HCl}$ fumigation is time consuming and not applicable to monitoring networks. As alternatives, a method based on a thermal pretreatment of the samples to remove $\mathrm{OC}$ and $\mathrm{EC}$ (i.e. $460^{\circ} \mathrm{C}$ for $60 \mathrm{~min}$ in an $\mathrm{O}_{2}$ atmosphere) followed by a total carbon determination (Jankowski et al., 2008), or the direct determination of the amount of $\mathrm{CO}_{2}$ produced by acidifying the sample, may be envisaged to measure $\mathrm{CC}$. 


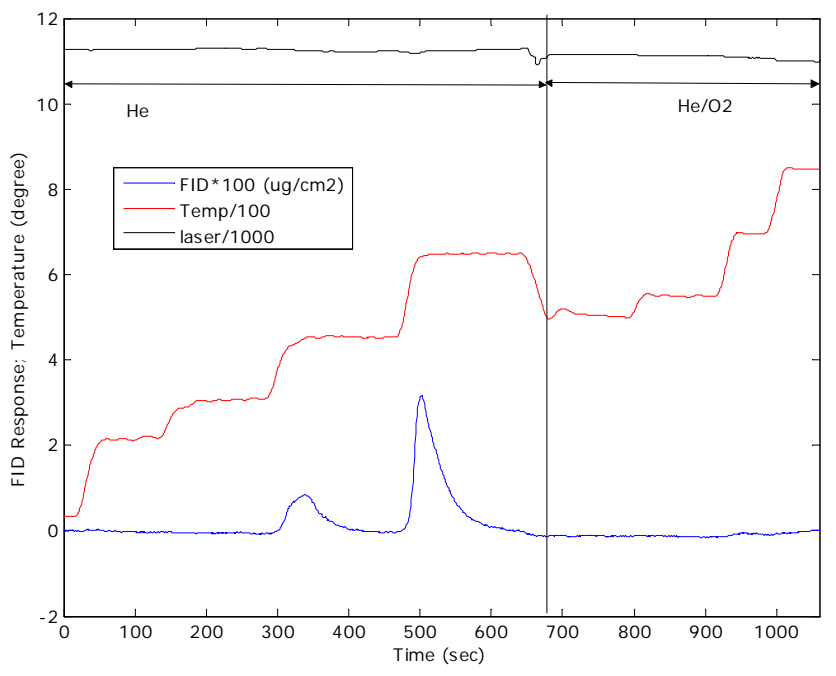

Fig. 3. Thermosgram from the analysis of natural calcite from Spain (grain dimension $\leq 300 \mu \mathrm{m}$ ) with the EUSAAR_2 protocol.

\subsection{Temperature plateau durations}

NIOSH and IMPROVE protocols also differ in the duration of their temperature steps (Table 1). The IMPROVE time steps are variable, since the shifting to the next temperature set-point is not initiated until the slope of the FID response reaches zero, whereas NIOSH protocols explicitly fix durations at each temperature set-point, often giving rise to overlapping in OC peaks. Typically, individual steps are longer for IMPROVE than for the NIOSH protocol. In this work, residence times at each temperature set-point have been explicitly specified so that i) FID response approaches the baseline before the next set-point, so that carbon peaks are welldefined, which might be useful for comparing the thermal properties of carbonaceous aerosol, and infer information on their predominant sources; and ii) the total analysis time remains suitable for routine monitoring applications.

Particularly crucial is the residence time of the highest He-mode temperature step which needs to be long enough to guarantee that no further pyrolysis and evolution of OC occur at this temperature. Similarly, the duration of the highest temperature step in the $\mathrm{He} / \mathrm{O}_{2}$-mode should allow LAC species to completely evolve before calibration, thereby preventing residual LAC from evolving in the methane calibration peak, biasing both the total LAC load and the calibration peak.

In the EUSAAR_2 protocol (Table 1), residence times at each temperature step were selected such that the various carbon peaks are separated for a vast majority (higher than $80 \%$ ) of the samples collected during different seasons and at various sites in Europe, with filter loadings ranging from 5 to $62 \mu \mathrm{gC} \mathrm{cm}{ }^{-2}$.

\subsection{The Helium/Oxygen-mode}

Ideally, the OC/EC split should occur in the $\mathrm{He} / \mathrm{O}_{2}$-mode, where the FID signal is low, so that the discrimination of $\mathrm{OC}$ and EC is less sensitive to the uncertainty in the split point position. Several studies were performed, varying the number of steps, their temperature and duration, to design the $\mathrm{He} / \mathrm{O}_{2}$-mode. In general, with a limited number of steps in $\mathrm{He} / \mathrm{O}_{2}$-mode, the occurrence of a split point at the maximum of a high carbon peak, as shown in Fig. 4a, was more frequent, whereas it was hindered with multiple desorption steps, by a smoother FID response profile over the entire $\mathrm{He} / \mathrm{O}_{2}$-mode (Fig. $4 \mathrm{~b}$ ) (More examples are shown in Fig. S3 from the Supporting Information, http://www.atmos-meas-tech.net/3/79/ 2010/amt-3-79-2010-supplement.pdf). We compared, in particular, the EUSAAR_1 (Table1) and EUSAAR_2 protocols, having two and four temperature steps, respectively, in the $\mathrm{He} / \mathrm{O}_{2}$-mode for eighteen samples. Uncertainties in the EC concentrations were calculated assuming an uncertainty of $\pm 3 \%$ for the laser value (Cary, personal communication, 2005). For the EUSAAR_1 protocol, the corresponding uncertainty in the EC concentration ranged from $3 \%$ to $15 \%$, whereas for the EUSAAR_2 protocol the uncertainty was generally lower, from $2 \%$ to $7 \%$. In short, the conditions for the $\mathrm{He} / \mathrm{O}_{2}$-mode in which uncertainty in the OC/EC split determination was minimised are the following: step $1500^{\circ} \mathrm{C}$ for $120 \mathrm{~s}$, step $2550^{\circ} \mathrm{C}$ for $120 \mathrm{~s}$, step $3700^{\circ} \mathrm{C}$ for $70 \mathrm{~s}$, and finally step $4850^{\circ} \mathrm{C}$ for $80 \mathrm{~s}$ (Table 1 ).

\section{Conclusions}

A detailed study has been performed to assess and then minimise the effects of various procedural events that can potentially magnify the inherent biases affecting the results of $\mathrm{OC}$ and EC analyses by thermal-optical methods. Our approach to improve the accuracy of the discrimination between OC and EC was based on four goals. First, as charring correction relies on assumptions that proved not to be commonly true, we reduced pyrolysis to minimum levels in favour of a maximum volatilisation of organic carbon by adding and prolonging steps at lower temperatures. Second, we minimised the potential negative bias in EC determination caused by early release of LAC including native $\mathrm{EC}$ at high temperature in the He-mode. Third, we minimised the potential positive bias in EC determination resulting from the slipping of residual $\mathrm{OC}$ into the $\mathrm{He} / \mathrm{O}_{2}$-mode and its potential evolution after the split point by maximizing the evolution and/or pyrolysis of $\mathrm{OC}$ at high temperature in the He-mode. Finally, we reduced the uncertainty arising from the position of the OC/EC split point on the FID response profile through multiple desorption steps in the $\mathrm{He} / \mathrm{O}_{2}$-mode.

Since both premature light absorbing carbon (LAC) evolution and slipping of non-light absorbing carbon into the $\mathrm{He} / \mathrm{O}_{2}$-mode occur over a range of temperature which 

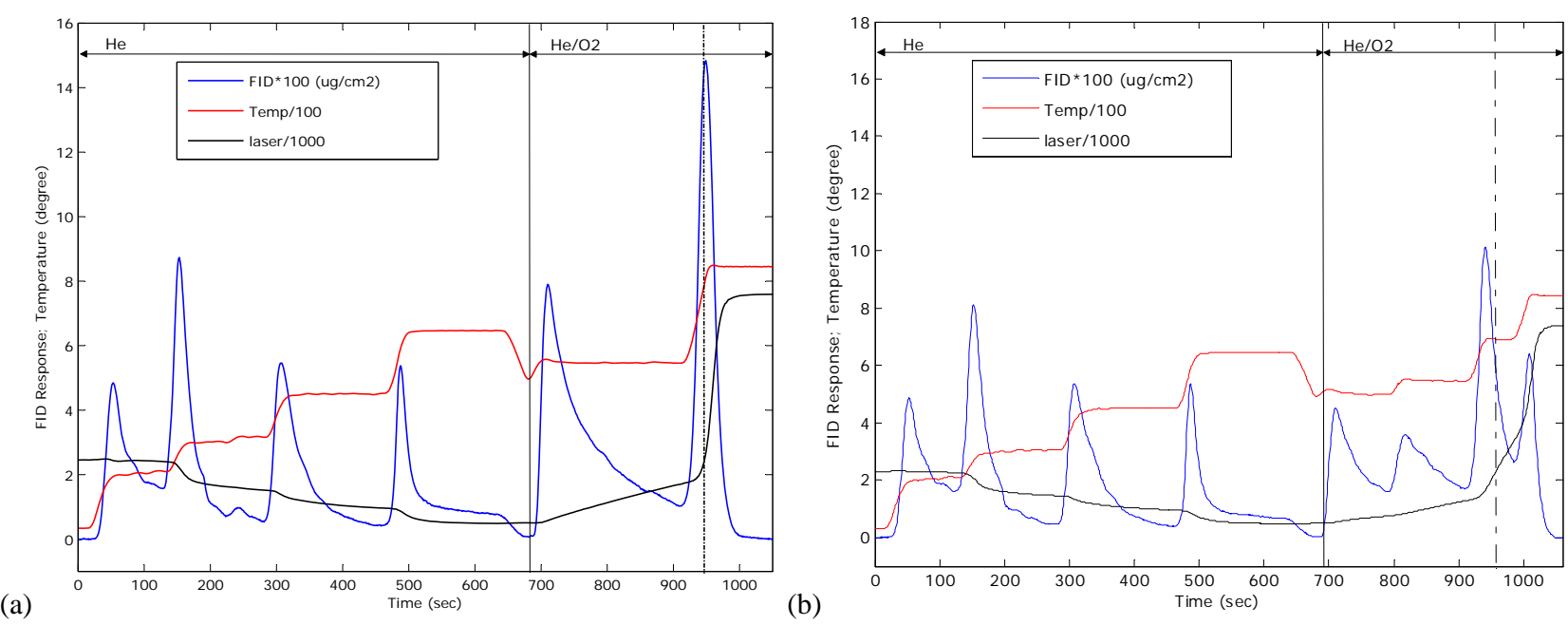

Fig. 4. Thermograms from the analysis of an aerosol sample with the EUSAAR_1 (a) and EUSAAR_2 (b) protocols.

depends on sample load and composition, specifying a single thermal protocol for which both biases would disappear is impossible. The present study indeed demonstrates the need to adopt a compromise that minimises these biases, respectively enhanced if too high and too low temperatures are reached in the He analytical mode. This work largely focused on the determination of the optimal value for this temperature. Analyses of ambient aerosol samples and of LAC-only samples were used to demonstrate that high temperatures in $\mathrm{He}\left(\geq 750^{\circ} \mathrm{C}\right)$ lead to premature LAC evolution possibly containing EC. For instance, more than $20 \%$ of LAC prematurely evolves when the maximum He-mode temperature is $850^{\circ} \mathrm{C}$ as in a NIOSH-type protocol. EC defined by this analysis is biased low because the optical correction for charring assumes that $\mathrm{PC}$ and native EC attenuation cross sections are equal, whereas $\sigma$ of PC is higher than $\sigma$ of EC. While this problem can be mitigated by lowering the maximum He-mode temperature, analyses of ambient aerosol samples and various organics-spiked filters indicate that a too low maximum $\mathrm{He}$-mode temperature $\left(\leq 550^{\circ} \mathrm{C}\right)$ allow $\mathrm{OC}$ to slip into the $\mathrm{He} / \mathrm{O}_{2}$-mode of the analysis. Only $55 \%$ of the OC from high molecular mass organic molecules evolves in the He-mode when the maximum He-mode temperature is $550{ }^{\circ} \mathrm{C}$ as in the IMPROVE protocol. If OC evolves after the $\mathrm{OC} / \mathrm{EC}$ split, it could bias the EC values high. Therefore, the best compromise is around $650{ }^{\circ} \mathrm{C}$, the highest temperature reached in the He-mode by the EUSAAR_2 protocol.

Studies were carried out involving aerosol samples collected at four EUSAAR sites across Europe, at Birkenes, Norway, at K-Puszta, Hungary, at Ispra, Italy, and at Montseny, Spain, that are characteristic of regionally distinct particulate matter mixtures. These studies gave a comprehensive overview of the thermal-optical behaviour of carbonaceous aerosol with diverse chemical properties: differences in the carbon fractions volatilised at the various temperatures and in the extent of the premature evolution of LAC were mainly observed. Among the various protocols we tested, those with a maximum temperature in $\mathrm{He}$ set at $650^{\circ} \mathrm{C}$, yield the lowest LAC pre-combustion and the minimum unevolved OC remaining and therefore, the most accurate estimation of EC.

The optimised thermal protocol EUSAAR_2 is defined as follows: step 1 in $\mathrm{He}, 200^{\circ} \mathrm{C}$ for $120 \mathrm{~s}$; step 2 in $\mathrm{He} 300^{\circ} \mathrm{C}$ for $150 \mathrm{~s}$; step 3 in $\mathrm{He} 450^{\circ} \mathrm{C}$ for $180 \mathrm{~s}$; step 4 in $\mathrm{He} 650^{\circ} \mathrm{C}$ for $180 \mathrm{~s}$. For steps $1-4$ in $\mathrm{He} / \mathrm{O}_{2}$, the conditions are $500^{\circ} \mathrm{C}$ for $120 \mathrm{~s}, 550{ }^{\circ} \mathrm{C}$ for $120 \mathrm{~s}, 700^{\circ} \mathrm{C}$ for $70 \mathrm{~s}$, and $850^{\circ} \mathrm{C}$ for $80 \mathrm{~s}$, respectively. EUSAAR 2 resulted as the best compromise for the analysis of $\mathrm{OC}$ and $\mathrm{EC}$ in different types of carbonaceous aerosol mixtures encountered across regional background sites in Europe.

The European atmospheric science community and monitoring networks (e.g. EMEP) are currently lacking an appropriate standardized method for the OC and EC determination. With respect to the currently used thermal protocols, the EUSAAR 2 protocol represents a valid alternative in which the potential biases have been minimised as much as possible given the intrinsic limitations of the thermal-optical method; and this can, in turn, ensure that OC and EC data sets obtained by various laboratories are comparable. This study represents as well a useful tool for understanding and interpreting the differences and potential biases in the measurements performed in the past across the world, and in turn, to possibly reconcile emission, atmospheric and modelled OC and EC data. The EUSAAR_2 protocol, together with other protocols including IMPROVE A, is currently under evaluation by a dedicated working group of the European Standardisation Committee (CEN) which will finally select the European standard protocol for thermal-optical OC and EC determination. 
Acknowledgements. We would like to acknowledge the support of the European Community - Research Infrastructure Action under the FP6 "Structuring the European Research Area" Programme, EUSAAR Contract No. RII3-CT-2006-026140. We also thank everyone involved in the planning and operation of these experiments.

Edited by: A. S. H. Prevot

\section{References}

Adar, S. D. and Kaufman, J. D.: Cardiovascular disease and air pollutants: Evaluating and improving epidemiological data implicating traffic exposure, Inhal. Toxicol., 19, 135-149, 2007.

Andreae, M. O. and Gelencsér, A.: Black carbon or brown carbon? The nature of light-absorbing carbonaceous aerosols, Atmos. Chem. Phys., 6, 3131-3148, 2006, http://www.atmos-chem-phys.net/6/3131/2006/.

BéruBé, K., Balharry, D., Sexton, K., Koshy, L., and Jones, T.: Combustion-derived nanoparticles: Mechanisms of pulmonary toxicity, Clin. Exp. Pharmacol. P., 34, 1044-1050, 2007.

Boparai, P., Lee, J., and Bond, T. C.: Revisiting Thermal-Optical Analyses of Carbonaceous Aerosol Using a Physical Model, Aerosol Sci. Tech., (42), 930-948, 2008.

Chow, J. C., Watson, J. G., Prithett, L. C., Pierson, W. R., Frazier, C. A., and Purcell, R. G.: The DRI Thermal/Optical Reflectance carbon analysis system: Description, evaluation, and applications in U.S. air quality studies, Atmos. Environ., 27A, 1185-1201, 1993.

Chow, J. C., Watson, J. G., Crow, D., Lowenthal, D. H., and Merrifield, T.: Comparison of Improve and NIOSH carbon measurements, Aerosol. Sci. Technol., 34, 23-34, 2001.

Chow, J. C., Watson, J. G., Chen, L. W. A., Arnott, W. P., and Moosmuller, H.: Equivalence of elemental carbon by thermal/optical reflectance and transmittance with different temperature protocols, Environ. Sci. Technol., 38, 4414-4422, 2004.

Chow, J. C., Watson, J. G., Chen, L.-W. A., Paredes-Miranda, G., Chang, M.-C. O., Trimble, D., Fung, K. K., Zhang, H., and Zhen, Yu, J.: Refining temperature measures in thermal/optical carbon analysis, Atmos. Chem. Phys., 5, 2961-2972, 2005, http://www.atmos-chem-phys.net/5/2961/2005/.

Chow, J. C., Watson, J. G., Chen, L.-W. A., Chang, M. C. O., Robinson, N. F., Trimble, D., and Kohl, S. D.: The IMPROVE_A temperature protocol for thermal/optical carbon analysis: Maintaining consistency with a long-term database, J. Air Waste Manage. Assoc., 57(9), 1014-1023, 2007.

Conny, J. M., Klinedinst, D. B., Wight, S. A., and Paulsen, J. L.: Optimizing thermal-optical methods for measuring atmospheric elemental (black) carbon: A response surface study, Aerosol Sci. Technol., 37, 703-723, 2003.

Fung, K.: Particulate carbon speciation by $\mathrm{MnO}_{2}$ oxidation, Aerosol Sci. Technol., 12, 122-127, 1990.

Gundel, L. A., Dod, R. L., Rosen, H., and Novakov, T.: The relationship between optical attenuation and Black carbon concentration for ambient and source particles, Sci. Total Environ., 36, 197-202, 1984.

Highwood, E. J. and Kinnersley, R. P.: When smoke gets in our eyes: The multiple impacts of atmospheric black carbon on climate, air quality and health, Environ. Int., 32, 560-566, 2006.
Han, Y., Cao, J., Chow, J. C., Watson, J. G., An, Z., Jin, Z., Fung, K., and Liu, S.: Evaluation of the thermal/optical reflectance method for discrimination between char- and soot-EC, Chemosphere, 69, 569-574, doi:10.1016/j.chemosphere.2007.03.024, 2007.

Hoffer, A., Gelencsér, A., Guyon, P., Kiss, G., Schmid, O., Frank, G. P., Artaxo, P., and Andreae, M. O.: Optical properties of humic-like substances (HULIS) in biomass-burning aerosols, Atmos. Chem. Phys., 6, 3563-3570, 2006, http://www.atmos-chem-phys.net/6/3563/2006/.

Jacobson, M. Z.: Strong radiative heating due to the mixing state of black carbon in atmospheric aerosols, Nature, 409, 695-697, 2001.

Jankowski, N., Schmidl, C., Marr., I. L., Bauer, H., and Puxbaum, H.: Comparison of methods for the quantification of carbonate carbon in atmospheric $\mathrm{PM}_{10}$ aerosol samples, Atmos. Environ., 42, 8055-8064, 2008.

Liousse, C., Cachier, H., and Jenning, S. G.: Optical and thermal measurements of black carbon aerosol content in different environments-variation of the specific attenuation cross-section, sigma, Atmos. Environ., 27, 1203-1211, 1993.

NIOSH Elemental Carbon (Diesel Particulate): Method 5040, www.cdc.gov./niosh/nmam/pdfs/5040f3.pdf, 1999.

Park, S. S., Kim, Y. J., and Fung, K.: PM 2.5 carbon measurements in two urban areas: Seoul and Kwangju Korea, Atmos. Environ., 36, 1287-1297, 2002.

Park, S. S., Bae, M. S., Schuauer, J. J., Ryu, S. Y., Kim, Y. J., Yong Cho, S., and Kim, S. J.: Evaluation of the TMO and TOT methods for OC and EC measurements and their characteristic in $\mathrm{PM}_{2.5}$ at an urban site of Korea during ACE-Asia, Atmos. Environ., 39, 5101-5112, 2005.

Peterson, M. R. and Richards, M. H.: Thermal-opticaltransmittance analysis for organic, elemental, carbonate, total carbon, and OCX2 in $\mathrm{PM}_{2.5}$ by the EPA/NIOSH method, in: Proceedings, Symposium on Air Quality Measurement Methods and Technology-2002, edited by: Winegar, E. D. and Tropp, R. J., Air \& Waste Management Association, Pittsburgh, PA, 83-1-83-19, 2002.

Petzold, A., Kopp, C., and Niessner, R.: The dependence of the specific attenuation cross-section on black carbon mass fraction and particle size, Atmos. Environ. 31, 661-672, 1997.

Petzold, A. and Schönlinner, M.: Multi-angle Absorption Photometry - A New Method for the Measurement of Aerosol Light Absorption and Atmospheric Black Carbon, J. Aerosol Sci. 35, 421-441, 2004.

Putaud, J-P., Raes, F., Van Dingenen, R., Brueggemann, E. Facchini, M. C., Decesari, S., Fuzzi, S., Gehrig, R., Hueglin, C., Laj, P., Lorbeer, G., Maenhaut, W., Mihalopoulos, N., Mueller, K., Querol, X., Rodriguez, S., Schneider, J., Spindler, G., ten Brink, H., Tørseth, K., and Wiedensohler, A. A.: European aerosol phenomenology-2: chemical characteristics of particulate matter at kerbside, urban rural and background sites in Europe, Atmos. Environ., 38, 2579-2595, 2004.

Ramanathan V. and Carmichael G.: Global and regional climate changes due to black carbon, Nat. Geosci., 1, 221-227, doi:10.1038/ngeo156, 2008. 
Schauer, J. J., Mader, B. T., Deminter, J. T., Heidemann, G., Bae, M. S., Seinfeld, J. H., Flagan, R. C., Cary, R. A., Smith, D., Huebert, B. J., Betram, T., Howell, S., Kline, J. T., Quinn, P., Bates, T., Lim, H. J., Yu, J. Z., Yang, H., and Keywood, M. D.: ACEAsia intercomparison of a thermal-optical method for the determination of particle-phase organic and elemental carbon, Environ. Sci. Technol., 37, 993-1001, 2003.

Schmid, H., Laskus, L., Abraham, H. J., Baltensperger, U., Lavanchy, V., Biazjak, M., Burba, P., Cachier, H., Crow, D., Chow, J., Gnauk, T., Even, A., ten Brink, H. M., Giesen, K.-P., Hitzenberger, R., Hueglin, C., Maenhaut, W., Pio, C., Carvahlo, A., Putaus, J.-P., Toom-Sauntry, D., and Puxbaum, H.: Results of the "carbon conference" international aerosol carbon round robin test stage I, Atmos. Environ., 35, 2111-2121, 2001.

Subramanian, R., Khlystov, A. Y., and Robinson, A. L.: Effect of peak inert-mode temperature on elemental carbon measured using thermal-optical analysis, Aerosol Sci. Technol., 40, 763-780, 2006.

Subramanian, R., Roden, C. A., Boparai, P., and Bond, T.: Yellow beads and missing particles: trouble ahead for filter-based absorption measurements, Aerosol Sci. Technol., 41, 630-637, 2007. ten Brink, H., Maenhaut, W., Hitzenberger, R., Gnauk, T., Spindler, G., Even, A., Chi, X., Bauer, H., Puxbaum, H., Putaud J.-P., Tursic, J., and Berner, A.: INTERCOMP2000: the comparability of methods in use in Europe for measuring the carbon content of aerosol, Atmos. Environ., 38, 6507-6519, 2004.

US EPA: Modification of Carbon Procedures in the Speciation Network and FAQs, $\mathrm{PM}_{2.5}$ speciation Trends Network Newsletter (April), http://www.epa.gov/ttn/amtic/files/ambient/pm25/spec/ spnews5.pdf, 2-3, 2006.

Watson, J. G., Chow, J. C., and Chen, L.-W. A.: Summary of organic and elemental carbon/black carbon analysis methods and intercomparisons, Aeros. Air Qual. Res., 5, 65-102, 2005.

Yang, H. and Yu, J. Z.: Uncertainties in charring correction in the analysis of elemental and organic carbon in atmospheric particles by thermal/optical methods, Environ. Sci. Technol., 36, 51995204, 2002.

Yu, J. Z., Xu, J., and Yang, H.: Charring characteristics of atmospheric organic particulate matter in thermal analyses, Environ. Sci. Technol., 36, 754-761, 2002.

Yu, J. Z. and Li, Q.: Charring minimisation in thermal analysis of aerosol carbon. EC/OC workshop in Durango, USA, 2003. 